\title{
Cursos Superiores de Tecnologia: análise dos dados do Censo da Educação Superior
}

Higher Education Technology Courses: analysis from Higher Education Census Data

\author{
Jaiser Tapia', Luiza da Silva Tapia", Lorena Vicini"'
}

\begin{abstract}
RESUMO
Tendo em vista a demanda por profissionais de nível superior, formados num curto período de tempo, fez com que os Cursos Superiores em Tecnologia tivessem destaque no cenário nacional. Dentre suas características, estes cursos devem possuir oferta em contextos sociais específicos (demandas e necessidades locais) associados a formação acadêmica de tempo reduzido (de 2 a 3 anos). Embora já existam desde a década de 1970, esses cursos tiveram maior ênfase a partir dos anos 2000, ocasião em que a legislação foi atualizada e, também ocorreu interesse por parte do governo o qual disponibilizou maiores incentivos fiscais nesta área. Neste trabalho utilizou-se análise descritiva exploratória, na qual realizou-se uma comparação entre os cursos ofertados por instituições públicas e privadas. Os dados analisados são referentes a quantificação dos cursos oferecidos, das vagas ofertadas, dos concluintes e, a análise das relações entre cursos, instituições, vagas e concluintes. Dos resultados obtidos, podem ser destacados o crescimento praticamente linear da oferta destes cursos, os contrastes entre os cursos ofertados pelas instituições privadas e públicas, e os baixos valores para o indicador de concluintes, o que remete às elevadas taxas de evasão.
\end{abstract}

Palavras-chave: Tecnólogos; Instituições de Ensino Superior; Taxas de evasão.

\begin{abstract}
An attempt by education agents to form professionals from higher education, to solve the demands of society, is the offer of Higher Education Technology Courses. Among their characteristics, these courses must be offered in specific social contexts (local demands and needs) associated with short time academic training (from 2 to 3 years). Although these courses have been in existence since the 1970s, they had a greater emphasis since the 2000s, when the Brazilian legislation was updated and for the government incentives. From descriptive exploratory study, conducted a comparative analysis of the courses offered by public and private institutions. Specifically, analysis about the quantification of courses offered, the study vacancies offered, the graduating students and the relationships between courses, institutions, vacancies and graduating students were conducted. The analysis were performed from the microdata of the Higher Education Census, provided by the Ministry of Education, including data of Census from 2008 to 2017. Among the results obtained, we can highlight the practically linear growth of the offer of these courses, the contrasts between the courses offered by private and public institutions, and the low values for the graduating indicator, which resumes the high dropout rates.
\end{abstract}

Keywords: Technologist; Higher Education Institutions; Dropout rates.

\footnotetext{
' Universidade Federal de Santa Maria, Santa Maria, Brasil. E-mail: jaisert@yahoo.com.br.

" Universidade Federal de Santa Maria, Santa Maria, Brasil. E-mail: lusilva91@gmail.com.

III Universidade Federal de Santa Maria, Santa Maria, Brasil. E-mail: vicini22@gmail.com.
} 


\section{INTRODUÇÃO}

Não é novidade no Brasil que o Governo Federal investiu ou incentivou a criação de cursos superiores com vistas a suprir as necessidades de mão de obra qualificada. Tal ação parte do pressuposto que a educação para o trabalho não fora convenientemente tratada, excluindo-a do caráter universal, conforme consta no Parecer 436/2001 do Conselho Nacional de Educação.

Os cursos de educação profissional tecnológica de graduação foram incluídos nas Diretrizes e Bases da Educação (LDB) na década de 1990 e a partir deste marco legal, os Cursos Superiores de Tecnologia (CSTs) passaram e passam por um processo de expansão. Com esta expansão, a temática dos CSTs vem sendo abordada por diversos autores que abordam elementos do contexto histórico, econômico, social e político e, enfatizam a política educacional brasileira. No entanto o que se verifica é a quase inexistente abordagem do cenário evolutivo e atual referente a estes cursos.

Neste cenário de mudanças, conforme Takahashi (2010), os cursos superiores de tecnologia foram reformulados com o intuito de atender as demandas do setor produtivo, associado à ampliação do acesso ao ensino superior. No entanto, somente a partir da década de 2000, que o Brasil começou a fomentar a educação superior profissional com uma visão estratégica de escolarização (TAKAHASHI, 2010). Segundo a autora, reflexões devem ser realizadas sobre esta questão por perguntas como: 0 que esta expansão significa? Isso representa uma mudança no ensino superior brasileiro?

No mesmo sentido para Rosetti Junior e Schimiguel (2011), os CST tem demonstrado uma significativa capacidade de adequação ao novo contexto do ensino superior, tendo em vista o período de conclusão de dois ou três anos, logo, menores que os das graduações convencionais. Ainda para os autores estes cursos permitem a formação superior com menor custo e grande afinidade com as necessidades empresariais no Brasil.

Os Cursos Superiores de Tecnologia tiveram destaque a partir da Lei $n^{\circ}$ 9.394/96LDB que incluiu a educação profissional no âmbito das diretrizes nacionais para educação. Mais recentemente, em 2008, o texto da LDB foi alterado pela Lei no 11.741 
que tratou de ajustar as nomenclaturas a serem adotadas, distinguindo os cursos profissionais de nível médio dos cursos de nível superior.

Considerando uma visão política dos CSTs, tem-se o Decreto 5.154/04 que instituiu a política para o desenvolvimento da educação profissional, que especificamente através do inciso III do Art. $1^{\circ}$, trata da previsão dos cursos de educação profissional tecnológica de graduação. Da LDB, transcreve-se: “Art.5 - Os cursos de educação profissional tecnológica de graduação e pós-graduação organizarse-ão, no que concerne aos objetivos, características e duração, de acordo com as diretrizes curriculares nacionais definidas pelo Conselho Nacional de Educação".

Assim, considerando as diretrizes curriculares, o Ministério da Educação elaborou o Catálogo Nacional de Cursos Superiores de Tecnologia (CNST). A $3^{\mathrm{a}}$ e atual edição do CNST foi aprovada pela Portaria MEC n 413, de 11 de maio de 2016, traz em sua estrutura 134 denominações de Cursos Superiores de Tecnologia, agrupados em 13 eixos tecnológicos. As versões anteriores do CNST foram publicadas em 2006 e 2010.

Considerando o aspecto histórico, Takahashi (2010) aborda de modo bastante completo a evolução destes cursos no Brasil. A autora destaca que estes cursos começaram a ser ofertados ainda na década de 70 quando persistia a visão de uma educação para o trabalho associada à formação profissional das classes menos favorecidas. A autora ressalta que esta influência histórica marcou o preconceito sobre a educação profissional em contrapartida aos cursos superiores plenos.

No entanto, por forte incentivo do governo este cenário passou e passa por uma grande transformação. Principalmente a partir do ano de 2009, com o programa de expansão e reestruturação das Universidades Federais, o REUNI, uma série de remodelações contribuíram para o desenvolvimento e implementação dos CSTs. Favretto e Moretto (2013) destacam algumas destas transformações, principalmente a regulamentação destes cursos pelas Diretrizes Curriculares Nacionais estabelecidas pelo Conselho Nacional de Educação. Outro aspecto também levantado é que o fato da exigência de titulação em nível superior para ingresso no mercado de trabalho também 
contribuiu para o desenvolvimento destes Cursos (NEVES, 2004; KUENZER, 1995; FAVRETTO E MORETTO, 2013; NEVES, RAIZER e FACHINETTO, 2007).

Ainda, Takahashi (2010), na oportunidade de seu estudo, observou que no contexto econômico e social a proliferação dos cursos superiores de tecnologia indicava um estágio de mudanças na história da educação profissional brasileira. Para a autora, o novo modelo de educação profissional e tecnológica, traduz uma tentativa de adequar à educação ás novas demandas sociais, ou seja, (mão de obra especializada e, de nível superior).

Nesse sentido, observa-se a tentativa governamental de acompanhar o movimento e exigências da sociedade, o que pode ser verificado a partir da atualização da legislação que versa sobre os cursos superiores de tecnologia. Assim evidenciamse os marcos legais sucessivos na última década, dos quais merecem destaque além do Catálogo Nacional de Cursos Superiores de Tecnologia e os pareceres da Câmara de Educação Superior vinculada ao Conselho Nacional de Educação.

Portanto, ao se abortar a questão dos Cursos Superiores em Tecnologia deve-se ter em mente algumas premissas fundamentais de sua concepção aliadas ao contexto histórico: ainda existe preconceito em relação aos CST? Os cursos atendem o objetivo de formar mão de obra qualificada para atender demandas locais? O mercado de trabalho é receptivo (adequadamente) aos egressos? Estas questões merecem atenção e podem refletir o entendimento social destes cursos no âmbito da formação profissional brasileira, conforme já apontado por TAKAHASHI (2010), CASTRO (2010), FAVRETTO e MORETTO (2013), ROSSETI JR e SCHMIGUEL (2011), SAMPAIO (2013) e CANCIAN (2016).

Contudo, embora se verifique na literatura trabalhos relacionados a contextos históricos, sociais e econômicos, nenhum deles abordou de forma direta algumas questões básicas da criação dos CST: Qual a demanda por estes cursos e estas vagas? Quantos são os alunos concluintes? O mercado de trabalho está receptivo a estes novos profissionais? Os alunos se formam no tempo previsto de duração do curso? A conclusão nestes cursos realmente garante a qualificação tecnológica? 
Portanto, no presente estudo, objetivou-se analisar a temática sob a ótica das vagas ofertadas e concluintes dos CSTs no âmbito das instituições abrangidas pelo Censo da Educação Superior do Ministério da Educação. Assim a partir dos dados do Censo da Educação Superior, especificamente buscou-se: a) quantificar os cursos oferecidos; b) quantificar as vagas ofertadas; c) quantificar os concluintes; e, d) analisar as relações entre cursos, instituições, vagas e concluintes.

Neste sentido, a inovação trazida pelo presente trabalho reside no sentido de demonstrar a possibilidade de explorar uma grande base de dados que se refere à educação superior brasileira. Assim, os autores esclarecem que se trata de um estudo inicial, mas não menos importante, que demonstra ao leitor uma lacuna de estudo pouco explorada tendo em vista o rol de informações coletados pelo Censo da Educação o Superior.

\section{ASPECTOS METODOLÓGICOS}

Tendo em vista a importância dos cursos Superiores em Tecnologia no Brasil, buscou-se desenvolver o presente trabalho, no qual utilizaremos uma análise descritiva, com o intuito de analisar os resultados obtidos, a partir dos dados coletados pelo Censo da Educação o Superior.

Aqui abordaremos uma análise descritiva exploratória, Gil (2010), explica que a pesquisa exploratória proporcionar maior familiaridade com o problema, com vistas a torná-lo mais explícito. Ainda, "objetivam proporcionar visão geral de um fenômeno ou fato social, que ainda não tenha sido objeto de estudos anteriores" (MEDEIROS, 2019). Assim, o caráter exploratório do presente estudo fundamenta-se na intenção de se aprofundar conhecimento e evidenciar como se caracterizam os cursos Superiores em Tecnologia no Brasil.

Já o aspecto descritivo, conforme seu nome já indica, reside na descrição do fenômeno ou fato observado. A pesquisa descritiva busca descrever as características de uma população, de um fenômeno e/ou dos processos que o compõe ou que nele ocorrem (GODOY, 1995; MEDEIROS, 2019). Desse modo, a pesquisa exploratória descritiva envolve a observação sistemática dos fatos, que são registrados, analisados, 
classificados e interpretados, sem a interferência do pesquisador (LAKATOS E MARCONI, 2007). A pesquisa pode ser considerada de natureza exploratória quando envolve estudos bibliográficos, levantamentos, entrevistas, análise que permite a compreensão do problema e análise de exemplos que estimulem a compreensão (GIL, 1999; MEDEIROS, 2019).

A pesquisa bibliográfica norteou o estudo no sentido de contextualizar o estado da arte referente às discussões acerca dos Cursos Superiores em Tecnologia no Brasil. Utilizou-se o modelo de revisão tradicional por se tratar de uma pesquisa abrangente sem uma questão específica (CORDEIRO et al, 2007). Já a pesquisa documental foi necessária para a contextualização da pesquisa no que tange os aspectos legais vigentes, ou seja, a legislação pertinente aos Cursos Superiores de Tecnologia. Quanto a pesquisa de levantamento esta se refere a obtenção dos dados propriamente ditos.

Com a pesquisa de levantamento obteve-se os dados disponíveis no sítio oficial do Ministério da Educação (MEC) e se tratam dos microdados do Censo da Educação Superior (CENSUP). Assim, sobre o CENSUP, o MEC explica que "é o instrumento de pesquisa mais completo do Brasil sobre as instituições de educação superior (IES) que ofertam cursos de graduação e sequencias de formação específica, além de seus alunos e docentes. Essa coleta tem como objetivo de oferecer à comunidade acadêmica e à sociedade em geral informações detalhadas sobre a situação e as grandes tendências do setor". Quanto aos Microdados, estes "se constituem no menor nível de desagregação de dados recolhidos por pesquisas, avaliações e exames realizados" (INEP, 2019).

Tendo em vista a variação da estrutura de apresentação dos Microdados para os diferentes anos, o primeiro procedimento foi o de tabular os dados de forma a agrupálos em banco de dados único e uniforme. Este agrupamento foi realizado para os dados que compreendem os Censos da Educação Superior de 2008 até 2017 (inclusive). Para auxiliar nestes procedimentos, foram utilizados software de planilha eletrônica, Microsoft Power Bl e Statistica $\circledR^{7}$.

A Figura 1 representa os procedimentos adotados quanto à organização e análise dos dados: 
Figura 1 - Fluxo dos procedimentos adotados

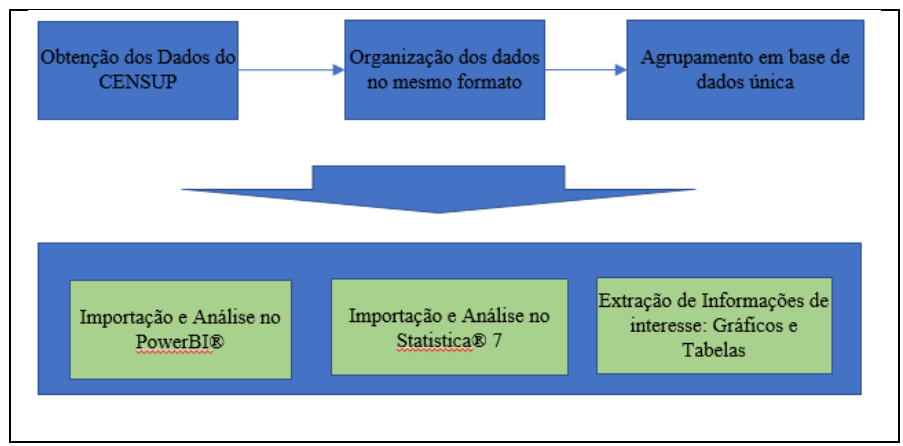

Fonte: Elaborado pelos autores.

Com base na estrutura de dados organizada, foram segregadas as informações para análise conforme as características dispostas no quadro a seguir:

Quadro 1 - Características consideradas para análise

\begin{tabular}{|c|c|}
\hline Característica & Valores Considerados \\
\hline Grau Acadêmico & Tecnólogo \\
\hline Período (anos) & $\begin{array}{l}2008 \text { - } 2017 \text { (referente ao ano da informação, } \\
\text { disponibilizados no ano subsequente) }\end{array}$ \\
\hline $\begin{array}{l}\text { Categorias } \\
\text { Administrativas } \\
\text { das Instituições }\end{array}$ & $\begin{array}{l}\text { 1. Pública Federal } \\
\text { 2. Pública Estadual } \\
\text { 3. Pública Municipal } \\
\text { 4. Privada com fins lucrativos } \\
\text { 5. Privada sem fins lucrativos }\end{array}$ \\
\hline $\begin{array}{l}\text { Organização } \\
\text { Acadêmica }\end{array}$ & $\begin{array}{l}\text { 1. Universidade } \\
\text { 2. Centro Universitário } \\
\text { 3. Faculdade } \\
\text { 4. Instituto Federal de Educação, Ciência e Tecnologia } \\
\text { 5. Centro Federal de Educação Tecnológica }\end{array}$ \\
\hline $\begin{array}{l}\text { Classificação das Áreas } \\
\text { do Conhecimento }\end{array}$ & $\begin{array}{l}\text { Classificação OCDE (Organização para Cooperação Econômica e } \\
\text { Desenvolvimento): } \\
\text { Agricultura e veterinária; Ciências sociais, negócios e direito; Ciências, } \\
\text { matemática e computação; Educação; Engenharia, produção e construção; } \\
\text { Humanidades e artes; Saúde e bem-estar social; Serviços. }\end{array}$ \\
\hline Modalidade de Ensino & $\begin{array}{l}\text { Presencial } \\
\text { Distância }\end{array}$ \\
\hline Vagas & Quantidade de vagas novas ofertadas \\
\hline Concluintes & Número de alunos concluintes \\
\hline $\begin{array}{l}\text { Relação entre } \\
\text { Concluintes e Vagas }\end{array}$ & Número de Concluintes em relação às vagas ofertadas: NCV \\
\hline Duração do Curso & Tempo em anos do tempo de formação normal informado no Censo \\
\hline
\end{tabular}

Fonte: Elaborado pelos autores.

Ainda, quanto à organização dos dados, considerou-se para fins de cômputo das vagas e concluintes o tempo de duração do Curso. Assim, para um curso com tempo de formação normal de 3 (três) anos, considerou-se o ano de ingresso adicionado tempo de duração normal (3) para obter-se o ano de conclusão. O mesmo vale para a 
obtenção dos ingressantes a partir do ano de conclusão, ou seja, ano de conclusão descontada a duração normal do curso para obter-se o ano de ingresso. Este procedimento foi adotado para amenizar diferenças de variação de oferta de vagas ao longo dos anos. Desse modo, embora a base de dados contemple os Censos dos anos de 2008 a 2017, em virtude da metodologia de divulgação dos resultados do CENSUP nos anos de 2008 a 2011, para fins de análise das vagas e concluintes considerou-se apenas o período em que foi possível obter o número de concluintes em função as respectivas vagas de ingresso.

Assim, de posse do conjunto de dados organizado, procedeu-se a análise descritiva dos dados, priorizando a extração de informações sobre cursos, vagas e concluintes.

\section{RESULTADOS E DISCUSSÕES}

Aqui apresentaremos alguns estudos já realizados na área e também a análise dos dados referente aos microdados do Censo da Educação Superior, disponibilizados pelo Ministério da Educação, compreendendo os Censos dos anos de 2008 até 2017, na qual consta a qualificação das áreas dos cursos, das instituições, das vagas, dos concluintes e da relação entre concluintes e vagas ofertadas.

Os estudos trazem em sua abordagem a avaliação histórica, perspectivas e contexto, bem como a preocupação em verificar se o objetivo proposto pelos cursos tecnológicos, resultando na empregabilidade dos egressos, está sendo obtido ou em outras palavras, tratam da absorção dos egressos pelo mercado de trabalho.

Para Takahashi (2010) o aumento na oferta desta modalidade está vinculado ao alinhamento de estratégias educacionais associadas às configurações sócio econômicas e políticas, para a inserção na economia globalizada. Ainda conforme a autora "a expansão da oferta dessa modalidade (...) pode trazer diferentes resultados que merecem ser avaliados". Espera-se que nesta modalidade as demandas sociais por mão de obra qualificada sejam rapidamente atendidas. Ainda, conforme a autora, marcos regulatórios trazem aos CSTs uma perspectiva de mudança no preconceito em relação à educação tecnológica, que era apenas procurada por pessoas de baixa renda. 
Neste mesmo contexto Cazarotti e Bernardes (2018), ratificam que os CSTs ainda são estigmatizados sendo considerados de qualidade inferior. Os autores sugerem ainda que estudos sejam realizados junto as empresas com vistas a "identificar se os profissionais formados nos cursos superiores de tecnologia atendem as demandas do mercado de trabalho, as demandas sociais e, também com os alunos desses cursos, para que eles relatem suas experiências, expectativas e críticas".

Sampaio (2013), aponta em seu estudo que a expansão dos CSTs "descentraliza a educação profissional e tecnológica", e "se constitui num diferencial na formação profissional dos egressos, com a capacidade de alterar positivamente a qualidade de vida destes". Assim conforme o autor, para os egressos a oferta de CST também representa melhoria individual.

Conforme Rossetti Junior e Schmiguel (2011) em virtude dos CSTs formarem profissionais diferenciados, cabe às empresas e organizações profissionais estarem "preparadas para lidar e trabalhar com esse enorme conjunto de novos graduados, afinados com demandas específicas do mercado".

Castro (2010) observou que "o desafio encontrado pelos tecnólogos no mercado de trabalho se relaciona a situação ocupacional assumida por estes profissionais, que acabam desenvolvendo funções não específicas de sua formação acadêmica" e, "mesmo com a necessidade de profissionais para ocuparem vagas específicas no mercado de trabalho, as empresas, ainda, os mantêm em uma posição ocupacional que não corresponde a sua formação de nível superior".

Para Favretto e Moretto (2010), embora exista a tendência de organizar a oferta de cursos em função das demandas imediatas do mercado, os CSTs tem enfrentado uma progressiva e expressiva ociosidade e com elevado índice de evasão.

A partir destes estudos os autores indicam que embora exista uma premissa estratégica para a criação dos CSTs, na prática ainda existem problemas de adequação dos cursos às necessidades sociais e elevados índices de evasão. Convém mencionar que a temática sobre os resultados da criação dos CSTs ainda é uma lacuna de pesquisa pouco explorada. 


\subsection{Análise dos dados}

Conforme dados do Censo da Educação Superior de 2017 (dados do último Censo divulgado até a conclusão deste trabalho), são oferecidos no Brasil 7.001 cursos de educação superior tecnológica e estão divididos entre Universidades (2155), Centros Universitários (1423), Faculdades (2899). Institutos Federais de Educação (519) e Centros Federais de Educação Tecnológica (5).

Do total dos cursos superiores, os CST representam 19,66\%. Comparativamente às outras modalidades de curso superior (bacharelado, licenciatura) e o número de CSTs é semelhante aos de cursos superiores em licenciatura (20,36\%). Nesse sentido, embora exista a predominância dos cursos de bacharelado $(59,10 \%)$, a quantificação do número de CSTs oferecidos conforme o último CENSUP praticamente se iguala ao número de cursos de licenciatura, ou seja, sendo estes tidos como cursos tradicionais.

A Tabela a seguir apresenta o resumo da composição dos cursos superiores por grau acadêmico conforme o CENSUP 2017.

Tabela 1 - Número e Percentual de Cursos Superiores por grau acadêmico no Brasil em 2017

\begin{tabular}{lcccccc}
\hline \multirow{2}{*}{$\begin{array}{l}\text { Grau } \\
\text { Acadêmico }\end{array}$} & \multicolumn{2}{c}{ Total } & \multicolumn{3}{c}{ Presencial } & \multicolumn{3}{c}{ EAD } \\
\cline { 2 - 7 } & Número de Cursos & $\%$ & Número de Cursos & $\%$ & Cursos & $\%$ \\
\hline Bacharelado & 21.046 & $59,10 \%$ & 20.521 & $57,63 \%$ & 525 & $1,47 \%$ \\
Licenciatura & 7.250 & $20,36 \%$ & 6.479 & $18,19 \%$ & 771 & $2,17 \%$ \\
Não Aplicável & & & & & & \\
ou ABI* & 312 & $0,88 \%$ & 308 & $0,86 \%$ & 4 & $0,01 \%$ \\
Tecnólogo & 7.001 & $19,66 \%$ & 6.190 & $17,38 \%$ & 811 & $2,28 \%$ \\
\hline & 35.609 & $100,00 \%$ & 33.498 & $94,07 \%$ & 2.111 & $5,93 \%$ \\
\hline
\end{tabular}

*ABI: Área básica de Ingresso.

Fonte: Censo da Educação Superior de 2017. Elaborado pelos autores.

A Figura 2 representa a evolução do número de CSTs nas instituições de curso superior brasileiras partir do ano de 2008 até o ano de 2017. 
Figura 2 - Evolução do número de CSTs

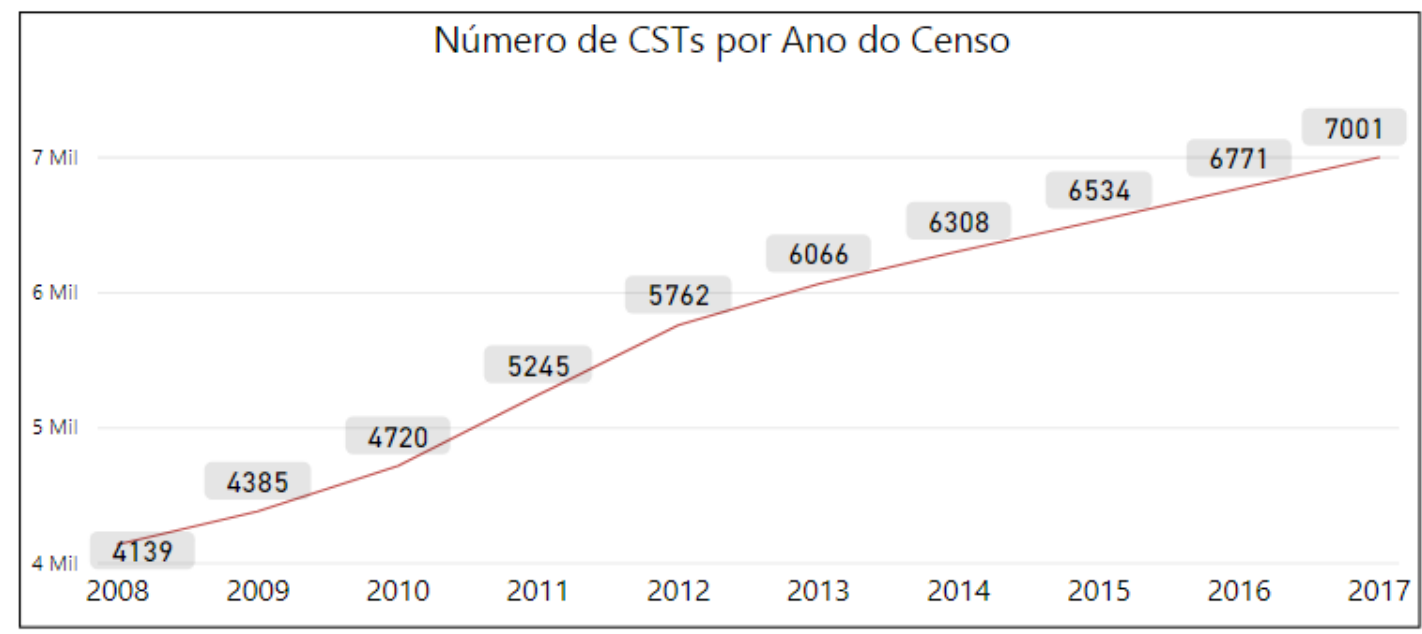

Fonte: Elaborado pelos autores.

Conforme a Figura 2 observa-se que na última década houve um crescimento praticamente linear da oferta de cursos superiores em tecnologia, tendo estes um aumento considerável.

Já na Figura 3, em conjunto com a Tabela 2, pode-se observar a evolução do número de cursos oferecidos pelas instituições de ensino de acordo com sua Categoria Administrativa:

Figura 3 - Evolução do número de CSTs por Categoria Administrativa

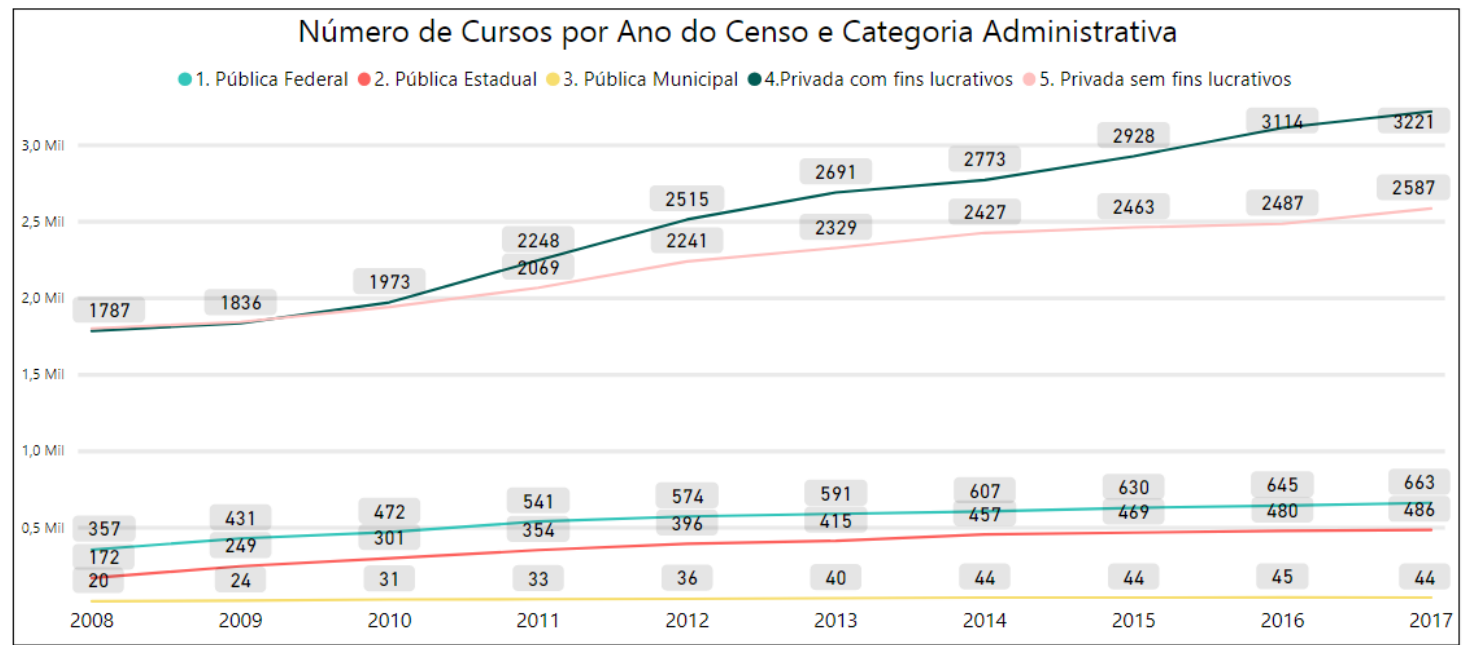

Fonte: Elaborado pelos autores. 
Tabela 2 - Variação Percentual do Número de Cursos Superiores de Tecnologia de 2008 a 2017

\begin{tabular}{lccccccc}
\hline \multirow{2}{*}{ Instituição } & \multicolumn{2}{c}{ Privada } & \multicolumn{3}{c}{ Pública } & \multicolumn{2}{c}{ Total } \\
\cline { 2 - 7 } & $\begin{array}{c}\text { Com Fins } \\
\text { Lucrativos }\end{array}$ & $\begin{array}{c}\text { Sem Fins } \\
\text { Lucrativos }\end{array}$ & Federal & Estadual & Municipal & Privada & Pública \\
\hline Cursos em 2017 & 3221 & 2587 & 663 & 486 & 44 & 5808 & 1193 \\
Cursos em 2008 & 1787 & 1803 & 357 & 172 & 20 & 3590 & 549 \\
\hline Variação \% & $80 \%$ & $43 \%$ & $86 \%$ & $183 \%$ & $120 \%$ & $62 \%$ & $117 \%$ \\
\hline
\end{tabular}

Fonte: Censo da Educação Superior de 2017. Elaborado pelos autores.

Ao analisarmos a evolução dos CSTs, conforme Figura 3 e considerando as Categorias Administrativas das instituições, verifica-se que a maior amplitude na criação de cursos pertence às instituições Públicas Estaduais, sendo que no período em estudo, passaram de 172 para 486 cursos, o que representa uma variação percentual de $183 \%$. Tal crescimento pode estar relacionado à ao fato de que os Cursos Superiores de Tecnologia devam ser direcionados a atender demandas locais, assim sendo pressupõe-se que as Instituições Estaduais tenham condições de identificar e atender estas demandas.

De forma semelhante, também ocorreu o aumento no número de cursos oferecidos pelas instituições municipais. Em termos percentuais a oferta de CSTs mais do que dobrou na última década. Esta variação também pode ser reflexo das políticas de educação de proporcionar cursos voltados para atendimento de demandas locais, conforme dispõe o Decreto 5.154/04.

Já as instituições Privadas com Fins Lucrativos tiveram um incremento de $80 \%$ no número de cursos tecnológicos oferecidos e as instituições Privadas sem fins lucrativos ofertaram novos cursos na ordem de $43 \%$, no período em análise.

Comparativamente à década anterior (2000 a 2009), tem-se o estudo de Takahashi (2010) que analisou a expansão dos CSTs naquele período. Conforme seu estudo, no período analisado pela autora, a expansão foi de $74 \%$ e os CSTs representavam em 2006, 15\% das graduações nacionais (Takahashi, 2010; MEC, 2006). Já conforme os dados em análise no presente estudo, verificou-se que a expansão destes cursos continua. No ano de 2008 foram informados ao CENSUP 4.355 cursos. Conforme os dados do CENSUP 2017 existem no Brasil 7.001 Cursos Superiores em 
Tecnologia. Logo, verifica-se que a expansão se mostrou considerável, com o aumento da oferta de cursos tecnológicos em $69 \%$.

Ainda, considerando apenas os dados do Censo de 2017, é possível descrever o cenário atual referente aos CSTs. Assim, o número de cursos ofertados por instituições privadas (5.808) é praticamente cinco vezes maior do que o número de cursos ofertados pelas instituições públicas (1.193). Dos cursos ofertados, as instituições privadas oferecem 782 cursos na modalidade de Ensino à Distância (EAD), o que representa $13,5 \%$ dos cursos destas instituições. Já as instituições públicas ofertam apenas 29 cursos EAD, que representa cerca de 2,5\% do total de cursos. A Tabela 3, a seguir, resume os dados referentes aos cursos ofertados (Censo de 2017), conforme as áreas da Classificação OCDE.

Tabela 3 - Número de cursos oferecidos por Área da Organização para Cooperação Econômica e Desenvolvimento conforme dados do Censo da Educação Superior de 2017

\begin{tabular}{|c|c|c|c|c|c|c|c|c|c|c|}
\hline \multirow{3}{*}{ Área Geral OCDE } & \multicolumn{5}{|c|}{ Privada } & \multicolumn{5}{|c|}{ Pública } \\
\hline & \multirow[b]{2}{*}{$\mathrm{EAD}^{2}$} & \multicolumn{3}{|c|}{ Presenci } & \multirow{2}{*}{$\begin{array}{c}\% \\
\text { Total }\end{array}$} & \multicolumn{2}{|l|}{ EA } & \multicolumn{2}{|c|}{ Presenci } & \multirow[b]{2}{*}{$\%$ Total } \\
\hline & & $\%$ & al & $\%$ & & $D$ & $\%$ & al & $\%$ & \\
\hline Agricultura e veterinária & 11 & $1,41 \%$ & 60 & $1,19 \%$ & $1,22 \%$ & 4 & $13,79 \%$ & 113 & $9,71 \%$ & $9,81 \%$ \\
\hline Ciências sociais, negócios & & & & 50,78 & 53,96 & & & & & \\
\hline e direito & 582 & $74,42 \%$ & 2552 & $\%$ & $\%$ & 11 & $37,93 \%$ & 279 & $23,97 \%$ & 6 24,31\% \\
\hline Ciências, matemática & & & & 15,20 & 14,27 & & & & & \\
\hline e computação & 65 & $8,31 \%$ & 764 & $\%$ & $\%$ & 3 & $10,34 \%$ & 258 & $22,16 \%$ & $621,88 \%$ \\
\hline \multicolumn{11}{|l|}{ Engenharia, produção } \\
\hline e construção & 14 & $1,79 \%$ & 381 & $7,58 \%$ & $6,80 \%$ & 2 & $6,90 \%$ & 311 & $26,72 \%$ & 6 26,24\% \\
\hline Educação & & & & & & & & 2 & $0,17 \%$ & $0,17 \%$ \\
\hline Humanidades e artes & 14 & $1,79 \%$ & 485 & $9,65 \%$ & $8,59 \%$ & 1 & $3,45 \%$ & 36 & $3,09 \%$ & $3,10 \%$ \\
\hline \multirow[t]{2}{*}{ Saúde e bem estar social } & 3 & $0,38 \%$ & 135 & $2,69 \%$ & $2,38 \%$ & & $0,00 \%$ & 14 & $1,20 \%$ & $1,17 \%$ \\
\hline & & & & 12,91 & 12,78 & & & & & \\
\hline \multirow[t]{3}{*}{ Serviços } & 93 & $11,89 \%$ & 649 & $\%$ & $\%$ & 8 & $27,59 \%$ & 151 & $12,97 \%$ & $13,33 \%$ \\
\hline & & 100,00 & & 100,00 & 100,00 & & 100,00 & & 100,00 & 100,00 \\
\hline & 782 & $\%$ & 5026 & $\%$ & $\%$ & 29 & $\%$ & 1164 & $\%$ & $\%$ \\
\hline
\end{tabular}

Fonte: Censo da Educação Superior de 2017. Elaborado pelos autores.

1 Organização para Cooperação Econômica e Desenvolvimento

2 Ensino à Distância

Com os dados da Tabela 3, é possível verificar que nas Instituições Privadas existe a predominância dos cursos da Área Ciências Sociais, Negócios e Direito, correspondendo a 53,96\% dos cursos. Dentro desta área geral encontram-se os cursos como de Gerenciamento e Administração (2.581 cursos) e Marketing e Publicidade (385 
cursos). Já nas instituições públicas, predominam os cursos relacionados às áreas de Engenharia, Produção, Ciências Sociais e Computação que apresentam porcentagens de 26,24\%. Dentro destas áreas estão os cursos como Automação, Materiais, Metalurgia, Processamento de Informação e de Administração.

Neste cenário também podemos observar junto às instituições privadas, o contraste do percentual de oferta de cursos na área de Engenharia, Produção e Construção (6,8\%) em relação aos Cursos da Área de Ciências Sociais (53,96\%). Já nas Instituições Públicas este contraste não é verificado, visto que os percentuais de oferta de cursos na área de Engenharia e Ciências Sociais são bastante próximos (26,24\% e $24,31 \%)$.

Por outro lado, além de se considerar o número de cursos existentes, deve-se analisar as vagas ofertadas e os respectivos concluintes, bem como a relação entre ambos (concluintes/vagas), número de concluintes em relação às vagas ofertadas (NCV).

Na Tabela 4 constam as informações referentes à oferta de vagas nos cursos superiores por grau acadêmico, conforme o CENSUP 2017.

Tabela 4 - Vagas Ofertadas por Grau Acadêmico conforme Censo da Educação Superior de 2017

\begin{tabular}{lcccccc}
\hline \multirow{2}{*}{ Grau Acadêmico } & \multicolumn{2}{c}{ Total } & \multicolumn{2}{c}{ Presencial } & \multicolumn{2}{c}{ EAD } \\
\cline { 2 - 7 } & Vagas & Percentual & Vagas & Percentual & Vagas & Percentual \\
\hline Bacharelado & 2.648 .381 & $42,88 \%$ & 2.133 .637 & $34,55 \%$ & 514.744 & $8,33 \%$ \\
Licenciatura & 1.489 .406 & $24,12 \%$ & 464.343 & $7,52 \%$ & 1.025 .063 & $16,60 \%$ \\
Não Aplicável ou & & & & & & \\
ABI & 25.259 & $0,41 \%$ & 25.259 & $0,41 \%$ & 0 & $0,00 \%$ \\
Tecnólogo & 2.012 .760 & $32,59 \%$ & 685.254 & $11,10 \%$ & 1.327 .506 & $21,50 \%$ \\
\hline & 6.175 .806 & $100,00 \%$ & 3.308 .493 & $53,57 \%$ & 2.867 .313 & $46,43 \%$ \\
\hline
\end{tabular}

Fonte: Censo da Educação Superior de 2017. Elaborado pelos autores.

Nas Figuras 4 e 5, encontra-se o número de vagas ofertadas em cursos superiores de tecnologia, bem como a porcentagem de concluintes em relação às vagas ofertadas (NCV), por categoria administrativa, conforme o CENSUP de 2017: 
Figura 4 - Vagas Ofertadas por Categoria Administrativa

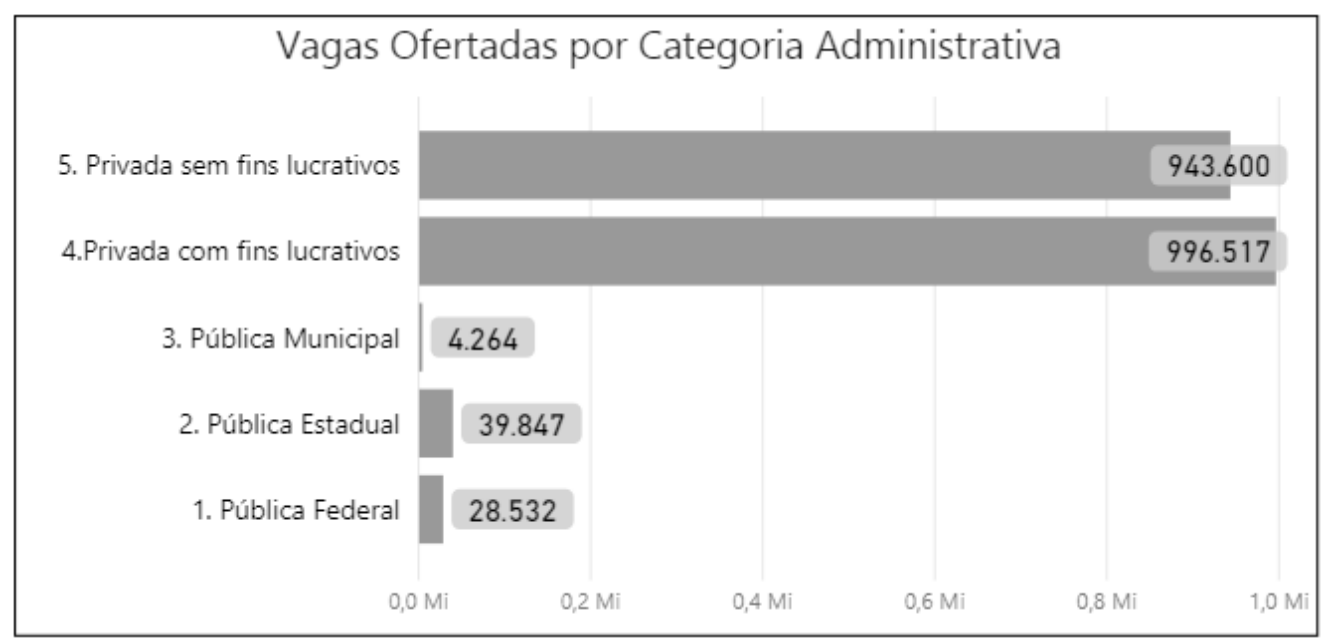

Fonte: Elaborado pelos autores.

Figura 5 - NCV percentual por Categoria Administrativa

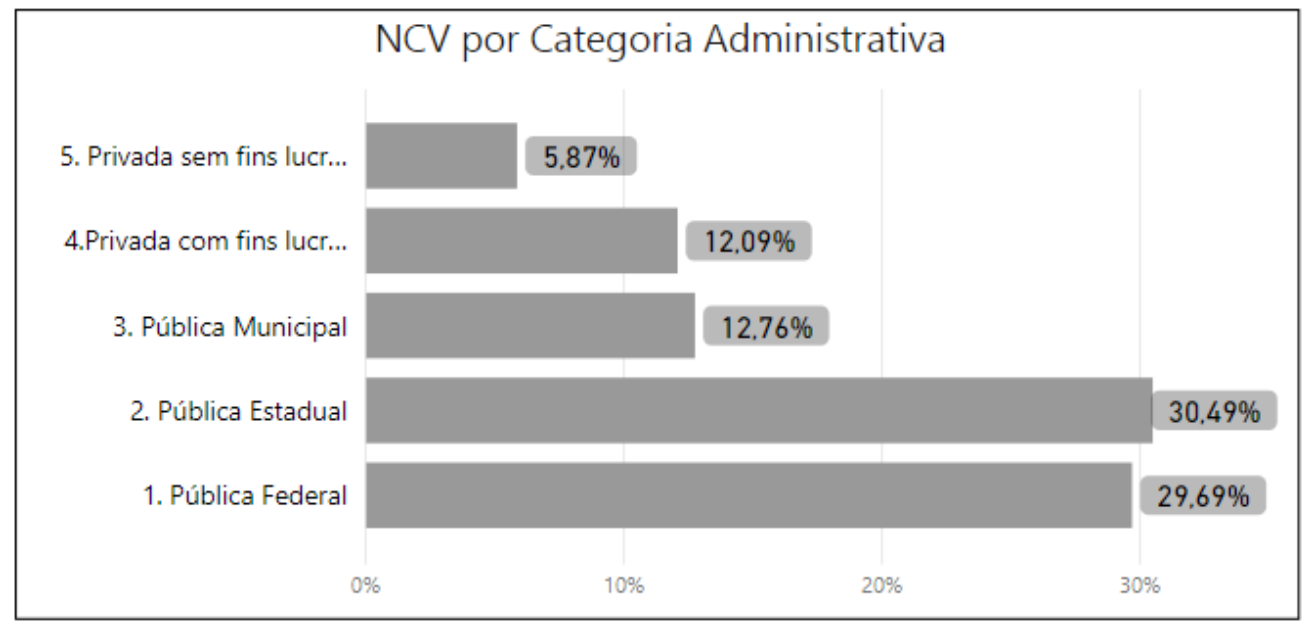

Fonte: Elaborado pelos autores.

Conforme as Figuras 4 e 5 é possível visualizar que embora as Instituições Privadas ofertem o maior número de vagas, o indicador de concluintes é o mais baixo (NCV= 5,87\% e 12,09\%). Já nas instituições públicas, o melhor indicador de conclusão pertence às Instituições Estaduais, que possuem o indicador de concluintes em relação às vagas ofertadas de $30,49 \%$.

Outra informação que pode ser destacada, conforme Figura 5, é o fato de que as instituições Públicas Municipais possuírem o menor indicador de NCV entre as instituições públicas. No entanto o seu NCV $(12,76 \%)$ ainda é maior que o NCV mais elevado das Instituições Privadas (12,09\%).

Analisando-se em separado as instituições privadas, e considerando as áreas do conhecimento da classificação geral da OCDE, têm-se as Figuras 6 e 7: 
Figura 6 - NCV percentual por Categoria Administrativa e Área OCDE

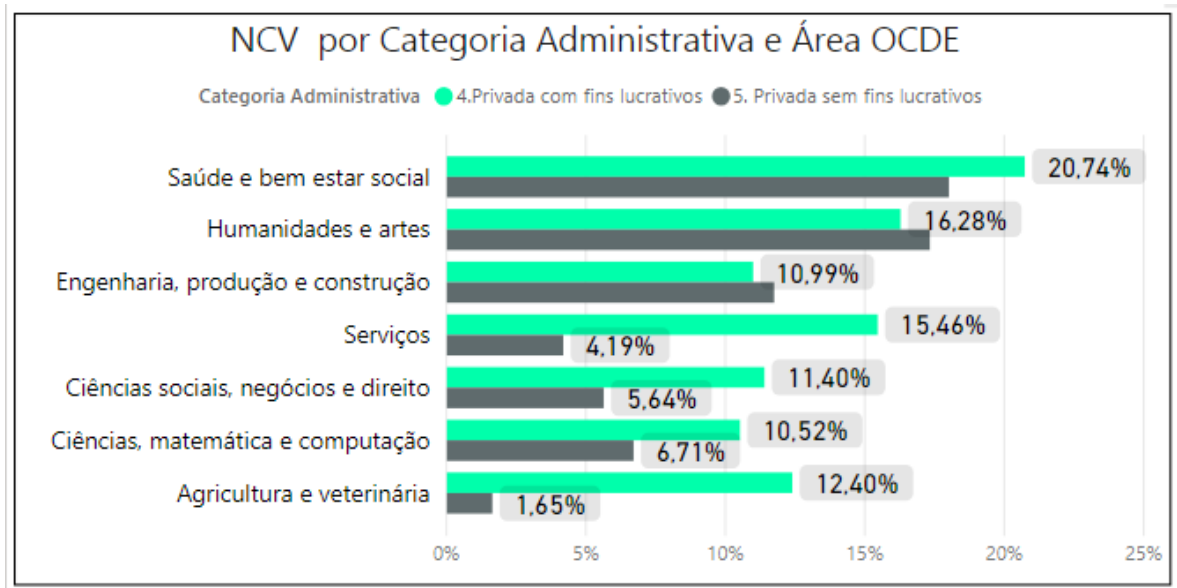

Fonte: Elaborado pelos autores.

Figura 7 - NCV percentual das Instituições Privadas e Área OCDE

\begin{tabular}{|c|c|c|c|c|}
\hline \multicolumn{5}{|c|}{ NCV (Instituições Privadas) e Área OCDE } \\
\hline Saúde e bem estar social & & & & $19.53 \%$ \\
\hline Humanidades e artes & & & & $16.72 \%$ \\
\hline Engenharia, produção e construção & & & $11,33 \%$ & \\
\hline Serviços & & $8.94 \%$ & & \\
\hline Ciências sociais, negócios e direito & & $8.78 \%$ & & \\
\hline Ciências, matemática e computação & & $8.62 \%$ & & \\
\hline Agricultura e veterinária & $2.52 \%$ & & & \\
\hline 0 & $5 \%$ & $10 \%$ & $15 \%$ & $20 \%$ \\
\hline
\end{tabular}

Fonte: Elaborado pelos Autores.

Embora que o NCV (2017) global das instituições Privadas seja de 5,87\% e 12,09\% conforme Figura 5, estes indicadores possuem a variação interna em virtude da área do conhecimento, conforme demonstrado na Figura 6. Exemplos desta variação podem ser visualizados a partir das Áreas de Agricultura e Veterinária, em que as Instituições Privadas com fins lucrativos possuem NCV de $12,40 \%$ e as sem fins lucrativos possuem NCV de 1,65\%, resultando no NCV conjunto de 2,52\%. O mesmo ocorre para a Área de Serviços, em que apresentam NCV de 15,46\% e 4,19\% para as instituições com fins lucrativos e sem fins lucrativos, respectivamente. Para o cálculo do NCV global ou conjunto utilizou-se o somatório dos concluintes e o somatório das vagas ofertadas.

A partir da Figura 7, considerando o número de vagas e concluintes das Instituições Privadas (com fins lucrativos e sem fins lucrativos conjuntamente), área de 
Saúde e Bem Estar Social apresenta o melhor indicador NCV (19,53\%), seguido das áreas de Humanidades e Artes (16,72\%) e Engenharia, Produção e construção (11,33\%).

Por outro lado, ao analisar os dados das instituições públicas, é possível verificar a existência de indicador NCV com valores elevados, que é o caso das Instituições Públicas Federais com indicador de 73,75\% na área de Educação. Convém destacar que são ofertados apenas dois cursos na Área de Educação, pelo Instituto Federal de Educação, Ciência e Tecnologia do Acre. As Figuras 8 e 9 a seguir permitem a visualização completa dos indicadores NCV por áreas da OCDE referente às instituições públicas, conforme os dados do CENSUP 2017.

Figura 8 - NCV percentual por Categoria Administrativa (instituições públicas) e Área OCDE

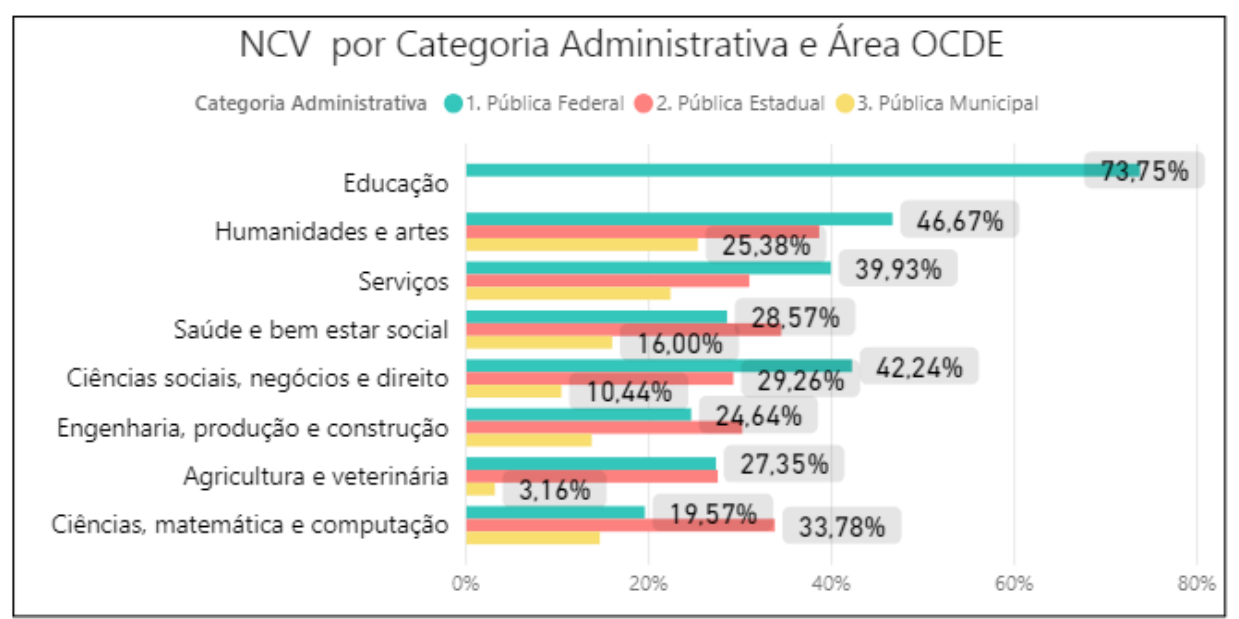

Fonte: Elaborado pelos autores.

Figura 9 - NCV percentual das Instituições Públicas e Área OCDE

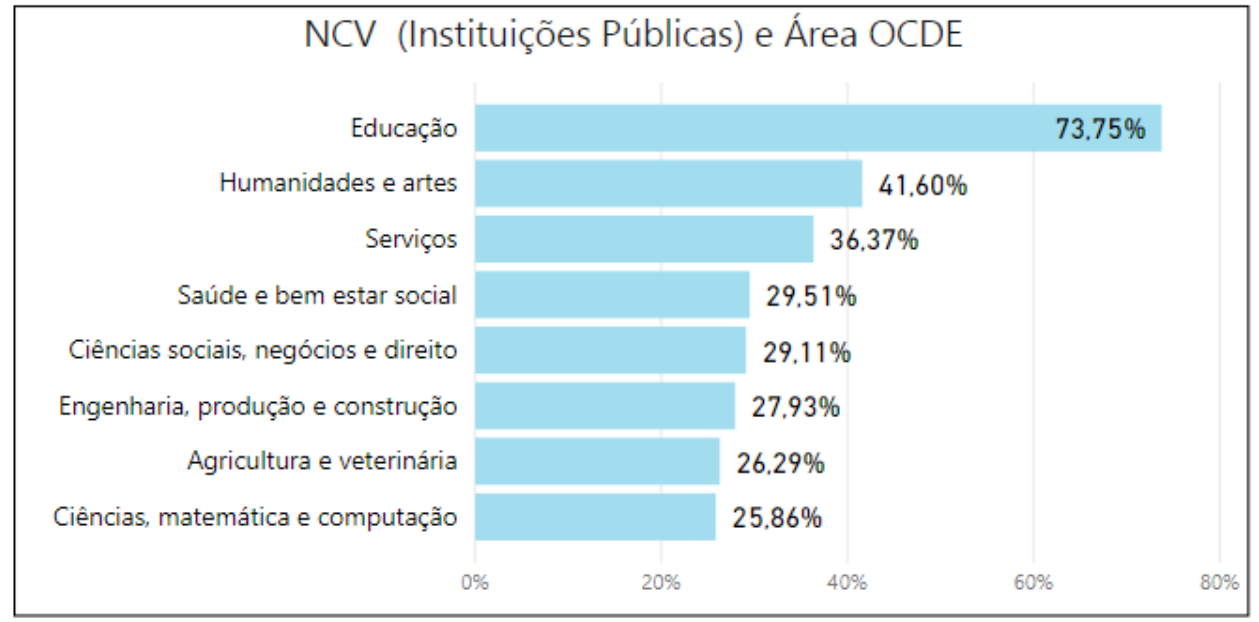

Fonte: Elaborado pelos autores. 
Considerando as Figuras 7 e 9 é possível realizar alguns comparativos entre os cursos ofertados pelas instituições Públicas e as Privadas. Ao se observar os valores para o NCV obtidos por área do conhecimento pode-se identificar que o menor indicador de conclusão encontrado para os cursos das instituições públicas $(25,86 \%)$ é maior que o indicador mais elevado obtido para as instituições privadas (19,53\%).

Ainda, considerando as mesmas áreas do conhecimento, o Indicador da Área Humanidades e artes nas Instituições Públicas $(41,60 \%)$ é 2,48 vezes maior que o indicador para a mesma área nas instituições privadas (16,72\%). Se considerarmos o extremo oposto, ou seja, o menor valor para o NCV, temos a área de Ciências, Matemática e Computação com 25,86\% nas Instituições Públicas, valor este que é 3 vezes maior que o NCV encontrado para as instituições privadas (8,62\%).

Assim, a partir da relação entre as vagas ofertadas e o número de alunos concluintes, é possível afirmar que as Instituições Públicas possuem mais alunos concluintes dos CSTs do que as Instituições Privadas. As Figuras 10 e 11 permitem visualizar esta diferença considerando os dados dos últimos 5 anos de Censo da Educação Superior (de 2013 a 2017).

Figura 10 - NCV (\%) acumulado dos anos de 2013 a 2017

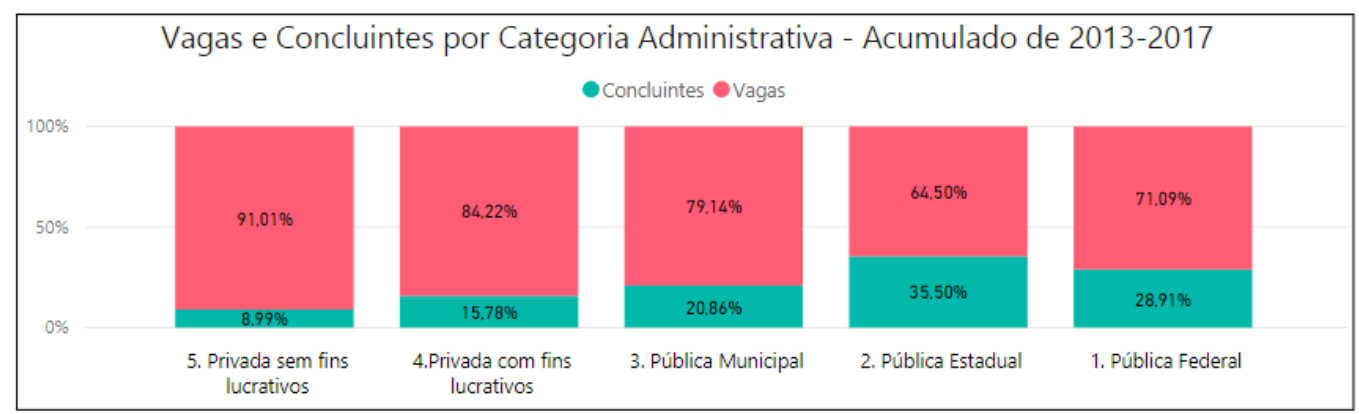

Fonte: Elaborado pelos autores.

Figura 11 - Evolução do NCV (\%) no período dos anos de 2013 a 2017

\begin{tabular}{|c|c|c|c|c|c|}
\hline \multicolumn{6}{|c|}{ Evolução do NCV por Categoria Administrativa } \\
\hline \multicolumn{6}{|c|}{ Categoria Administrativa 1. Pública Federal 2. Pública Estadual 3. Pública Municipal 4.Privada com fins lucrativos $\bullet$ 5. Privada sem fins lucrativos } \\
\hline $40 \%$ & $34.30 \%$ & $34.85 \%$ & $41.04 \%$ & $33.50 \%$ & \\
\hline $30 \%$ & $27.56 \%$ & $27.21 \%$ & $28.85 \%$ & $29.70 \%$ & $29.69 \%$ \\
\hline \multirow{2}{*}{$20 \%$} & 24020 & $18.24 \%$ & $26.89 \%$ & $26.15 \%$ & \\
\hline & $19.53 \%$ & $17.93 \%$ & & $13.17 \%$ & $12.09 \%$ \\
\hline \multirow[t]{2}{*}{$10 \%$} & $11.48 \%$ & $11.49 \%$ & $17.11 \%$ & & $12.76 \%$ \\
\hline & 1,4070 & & $10.04 \%$ & $8.03 \%$ & $5.87 \%$ \\
\hline $0 \%$ & 2013 & 2014 & 2015 & 2016 & 2017 \\
\hline
\end{tabular}

Fonte: Elaborado pelos autores. 
Observando a Figura 11, no período que compreende os anos de 2013 a 2017, verifica-se a oscilação no número de concluintes dos cursos Superiores de Tecnologia em praticamente todas as categorias administrativas das instituições. A exceção se verifica nas Instituições Públicas Federais em que o Indicador NCV se manteve praticamente constante.

Convém lembrar que o indicador NCV compara as vagas ofertadas e os seus respectivos concluintes. Logo o declínio nos valores do NCV indica que a alteração no número de concluintes ou na quantidade de vagas ofertadas não ocorreu de forma proporcional. Em outras palavras, os cursos novos ou o acréscimo de vagas em cursos existentes não refletiram no aumento de egressos na mesma proporção, ou ainda, para os cursos que não houve alteração das vagas, ocorreu uma redução no número de concluintes.

Sob esse aspecto, remete-se aos estudos anteriores e a legislação, conforme já abordado. Quanto à legislação o pressuposto dos CSTs é objetivo: devem atender a demandas sociais locais na formação de Técnicos de Nível Superior. Mediante a pesquisa realizada, foram encontrados estudos sobre a capacidade do mercado de trabalho de absorver estes egressos CANCIAN (2016); SAMPAIO (2013); FAVRETTO E MORRETTO (2013); CASTRO (2010). Assim, os baixos valores de NCV podem indicar a perda ou baixa adesão da sociedade aos egressos dos CSTs ocasionando a desistência dos alunos já matriculados, bem como a redução na adesão de novos alunos. Ou ainda, a redução de oportunidades de trabalho pode impactar diretamente na desistência de alunos ou reduzir a procura por determinados cursos.

Nesse mesmo sentido, retomando-se a evolução apresentada na Figura 2, em que o número de cursos foi crescente, comparativamente a Figura 11, que representa a evolução do número de concluintes em relação às vagas ofertadas, constata-se que o aumento da oferta de cursos e vagas não refletiu diretamente no número de egressos. Oportunamente deve-se considerar uma avaliação dos cursos criados quanto a sua real adequação as necessidades da sociedade, premissa básica da existência dos cursos superiores de tecnologia. 


\section{CONCLUSÃO}

A partir da análise das informações oficiais do Governo Federal, representadas pelos dados do Censo da Educação Superior, realizou-se o estudo sobre os Cursos Superiores de Tecnologia no Brasil, verificando-se que nas últimas décadas a oferta destes cursos apresentou significativo crescimento. Sem dúvida a atualização nos aspectos legais norteadores da concepção destes cursos, bem como a tentativa de promover maior integração entre as demandas da sociedade e as políticas governamentais para a educação tem contribuído para a alavancagem na criação dos CSTs.

Valendo-se da análise do indicador NCV, conclui-se que as Instituições Privadas possuem menor indicador de concluintes em relação às vagas ofertadas, quando comparadas com as Instituições Públicas. Foi possível verificar também que as Instituições Públicas formam mais Tecnólogos, do que em ralação as Instituições Privadas. Convém destacar que dentre as Instituições Públicas, as Municipais possuem o menor indicador NCV e, mesmo assim é maior do que os indicadores das Instituições Privadas.

Quanto às Áreas de conhecimento, verificou-se que nas Instituições Privadas existe a predominância de cursos dá Área de Ciências Sociais, Marketing e Direito, enquanto nas Instituições Públicas predominantemente são oferecidos cursos das Áreas de Engenharias, Matemática e Computação e, Ciências Sociais.

Do mesmo modo que estudos realizados anteriormente e que abordaram o contexto dos CSTs na década anterior, com ênfase para o trabalho de Takahashi (2010), que analisou os dados dos anos de 2000 a 2009, no presente trabalho também verificou-se que os índices de evasão permanecem elevados, ou como tratado por estes autores, o indicador de concluintes NCV se mostra baixo, principalmente ao se comparar o crescente aumento na oferta de cursos e vagas com a desproporção no número de concluintes.

Ainda foi possível verificar que a expansão no número de cursos ofertados e consequentemente o aumento no número de vagas oferecidas não se refletiu de maneira equitativa no número de concluintes. 
Considerando as instituições públicas e privadas, embora as instituições públicas tenham melhor indicador de concluintes, a taxa de não concluintes ainda é elevada, ficando na faixa dos $70 \%$.

Finalmente, a partir do pressuposto básico norteador da criação dos CSTs, que se refere à formação de mão de obra de nível superior, em menor tempo, visando atender as demandas da sociedade e, confrontando-se este pressuposto com os dados analisados e resultados obtidos, verificou-se que o número de concluintes é desproporcional em relação às vagas ofertadas. De outro modo, o baixo número de concluintes pode refletir que em algumas áreas do conhecimento não existe demanda por parte da sociedade que justifique a criação ou manutenção do curso. Assim uma análise mais oportuna por parte das instituições nos parece coerente no sentido de se evitar a criação de cursos novos que possam ter baixa adesão e/ou elevados índices de evasão. 


\section{REFERÊNCIAS}

CANCIAN RAS. Perfil e empregabilidade dos egressos dos Campi Agropecuários de Colorado do Oeste e Ariquemes do Instituto Federal de Educação, Ciência e Tecnologia de Rondônia [Dissertação]. Brasília: Programa de Pós Graduação em Gestão Pública/UNB; 2016. 76p.

CASTRO AMA. Ocupação do tecnólogo no mercado de trabalho: um estudo comparativo dos cursos superiores de tecnologia do Instituto Federal do Norte de Minas Gerais [Dissertação]. Brasília: Faculdade de Educação/UNB; 2010. 115p.

CAZAROTTI MLB, BERNARDES STA. Cursos Superiores de Tecnologia: fundamentos, controvérsias \& desafios. Revista on Line de Política e Gestão Educacional. 2019:22(3): 992-1046.

CORDEIRO MA., OLIVEIRA GM, RENTERIA JM, GUIMARÃES CA. Revisão sistemática: uma revisão narrativa. Revista do Colégio Brasileiro de Cirurgiões. 2007:34(6):428431.

DECRETO $n^{\circ} 5.154 / 2004$ DE 23 DE JULHO DE 2004. Regulamenta o § $2^{\circ}$ do art. 36 e os arts. 39 a 41 da Lei $\mathbf{n}^{\circ} \mathbf{9 . 3 9 4}$, de 20 de dezembro de 1996, que estabelece as diretrizes e bases da educação nacional, e dá outras providências. Diário Oficial da União (Brasília). 2004. jul. 26.

FAVRETTO J, MORETTO CF. Os Cursos Superiores de Tecnologia no contexto de expansão da educação superior no Brasil: A retomada da ênfase na Educação Profissional. Educação e Sociedade. 2013: 34(123): 407-424.

GIL AC. Métodos e técnicas de pesquisa social. São Paulo: Atlas, 1999.

GIL AC. Como elaborar projetos de pesquisa. São Paulo: Atlas, 2010.

GODOY A. Introdução a pesquisa Qualitativa e suas possibilidades. Revista de Administração de Empresas. São Paulo, V 35. N.2, p. 57-63, 1995.

INEP [internet]. Microdados. Acesso em 10 jan 2019. Disponível em http://portal.inep.gov.br/web/guest/microdados.

INEP [Internet]. Ministério da Educação. 0 que é o censo da Educação Superior. Disponível: em http://inep.gov.br/censo-da-educacao-superior. Acesso em: 10 jan. 2019.

KUENZER, AZ. A reforma do ensino técnico no Brasil e suas consequências. Ensaio: avaliação e políticas públicas em Educação. 1995: 6(20): 365-384. 
LAKATOS EM, MARCONI MA. Metodologia do trabalho científico. 17.ed. São Paulo: Atlas, 2007.

LEI No 9.394/96 DE 20 DE DEZEMBRO DE 1996. Estabelece as diretrizes e bases da educação nacional. Diário Oficial da União (Brasília). 1996. Dez. 23.

LEI No 11.741/08 DE 160 DE JULHO DE 2008. Altera dispositivos da Lei no 9.394, de 20 de dezembro de 1996, que estabelece as diretrizes e bases da educação nacional, para redimensionar, institucionalizar e integrar as ações da educação profissional técnica de nível médio, da educação de jovens e adultos e da educação profissional e tecnológica.. Diário Oficial da União (Brasília). 2008. jul. 17.

MEC [internet]. Ministério da Educação; Cursos Superiores de Tecnologia. Catálogo Nacional de Cursos Superiores de Tecnologia. Disponível em: http://portal.mec.gov.br/catalogos-nacionais-de-cursos-superiores-de-tecnologia. Acesso em: 15 jan. 2019.

MEDEIROS JB. Redação Científica prática de fichamentos, resumos, resenhas. 13. ed. São Paulo: Atlas, 2019.

MINISTÉRIO DA EDUCAÇÃO; Conselho Nacional de Educação. Parecer CNE 436/2001 - Cursos Superiores de Tecnologia - Formação de Tecnólogos. Brasília (Brasil): Ministério da Educação; 2001.

MINISTÉRIO DA EDUCAÇÃO [internet]; Escola de Gestores da Educação Convalidação de estudos. Cursos Superiores de Tecnologia. Disponível em: http://portal.mec.gov.br/escola-de-gestores-da-educacao-basica/323-secretarias112877938/orgaos-vinculados-82187207/12880-cursos-superiores-de-tecnologia. Acesso em: 15 jan. 2019.

NEVES, CEB. Universidade brasileira: equidade, qualidade e cidadania. Coimbra, $2004 . \quad$ Disponível em: https://www.ces.uc.pt/lab2004/inscricao/pdfs/painel44/ClarissaNeves.pdf. Acesso em: 10 jul. 2019

NEVES, CEB, RAIZER L, FACHINETTO RF. Acesso, expansão e equidade na educação superior: novos desafios para a política educacional brasileira. Sociologias. 2007: 9(17): 124-157.

PORTARIA n 413, DE 11 DE MAIO DE 2016. Aprova, em extrato, o Catálogo Nacional de Cursos Superiores de Tecnologia. Diário Oficial da União (Brasília). 2016. mai. 12. 
ROSETTI JUNIOR, H, SCHMIGUEL, J. Histórico e contexto econômico dos cursos superiores de tecnologia no Brasil. Observatorio de la Economia Latino-americana. 2011: 152. Disponível em: http://www.eumed.net/cursecon/ecolat/br/11/rjs.htm.

SAMPAIO, MVD. Educação Profissional: a expansão recente do IFRN e a absorção local dos egressos no mercado de trabalho [Dissertação]. Natal: Programa de PósGraduação em Economia/UFRN. 2013. 183 p.

TAKAHASHI, ARW. Cursos superiores de tecnologia em gestão: reflexões e implicações da expansão de uma (nova) modalidade de ensino superior em administração no Brasil. Revista de Administração Pública - RAP. 2010:44(2):385-414. 